\title{
Kahramanmaraş İlinde Sera Koşullarında Tuta absoluta (Meyrick) (Lepidoptera: Gelechiidae) (Domates güvesi) 'nın Popülasyon Yoğunluğu
}

\author{
M. Murat ASLAN ${ }^{1}$ \\ Serpil GENÇOĞLAN² \\ Günay AYGEL ${ }^{3}$ \\ Ceyda ÜCÜK ${ }^{3}$ \\ ${ }^{1}$ Kahramanmaraş Sütçü İmam Üniversitesi Ziraat Fakültesi Bitki Koruma Bölümü, Kahramanmaraş \\ ${ }^{2}$ Kahramanmaraş Sütçü İmam Üniversitesi Ziraat Fakültesi Biyosistem Mühendisliği Bölümü, Kahramanmaraş \\ ${ }^{3}$ Kahramanmaraş Sütçü İmam Üniversitesi Ziraat Fakültesi Bitki Koruma Bölümü, Kahramanmaraş \\ $\triangle$ : aslan@ksu.edu.tr
}

Geliş (Received): 18.01.2017

Kabul (Accepted): 13.04.2017

ÖZET: Ülkemizde kapalı ve açık alanlarda yetiştirilen domatesin en önemli zararlı durumuna gelen domates güvesi (Tuta absoluta (Meyrick) (Lepidoptera, Gelechiidae), bitkinin kök hariç tüm organlarında beslenmekte ve ekonomik olarak önemli ürün kayıplarına neden olmaktadır. Bu çalışmada Kahramanmaraş ili ve çevresinde domates güvesinin yaygınlığı ve popülasyon yoğunluğu belirlenmesi amacı ile Kahramanmaraş/Türkoğlu domates sera alanlarında $T$. absoluta'nın ilk ergin çıkış zamanı, popülasyon yoğunluğu, tahmini döl sayısı belirlenmeye çalışılmıştır. Domates güvesi çıkış zamanını belirlemek ve popülasyon yoğunluğunu saptamak amacıyla Delta tipi tuzaklar kullanılmıştır. Tuzaklarda yakalanan ergin sayıları incelendiğinde, en fazla ergin sayısı 486 adet olarak (6 Haziran 2011) tarihinde tespit edilmiştir. Seralarda yakalanan toplam T. absoluta ergin sayısı 10272 adet olarak belirlenmiştir. Nisan ayından itibaren seralarda çok sayıda insektisit kullanılmış olup, T. absoluta larvaları biyolojileri gereği açtıkları tünel ve galerilerde korunaklı olduklarından insektisitlerin etkisinin düşük olduğu belirlenmiştir. Bu nedenle, domates fidelerinin dikildiği tarihten itibaren tuzakların kurulması gerektiği, seralardaki tuzak sayılarının artırılması ve kapsüllerin sık aralıklarla değiştirilmesinin domates güvesi mücadelesinde önemli olduğu belirlenmiştir.

Anahtar sözcükler: Domates, domates güvesi, Tuta absoluta, popülasyon yoğunluğu

\section{Population Density of Tomato Leafminer Tuta absoluta (Meyrick) (Lepidoptera: Gelechiidae)'s in Greenhauses in Kahramanmaraş Province}

\begin{abstract}
In Turkey, tomato moth (Tuta absoluta (Meyrick) (Lepidoptera, Gelechiidae) is causing serious damage on all plant parts of tomato with the exception of the roots in open fields and green houses. In this study, in order to investigate the population frequency and density of T. absoluta, the first adult emergence time, population density and number of estimate generation of it was determined in greenhouses of Kahramanmaras/Turkoglu province. Delta type trap was used to determine emergence time of the tomato moth and population density. The highest mean number of adults was found as 486 (June 6, 2011). The total numbers of $T$. absoluta adults captured in traps, in greenhouses, were 10272. Insecticides were applied to T. absoluta from beginning of April to the end of growing season, as needed. However, the effect of insecticides were low due to T. absoluta biology and forming tunnels and galleries inside the host. Thus, it is very important that from beginning of transplanting date of tomatoes, the traps should be set, the trap numbers should be increased and the capsules should be frequently replaced.
\end{abstract}

Key Words: Tomato, tomato moth, Tuta absoluta, population density

\section{GİRIS}

Domatesin anavatanı Güney ve Orta Amerika olup tek yıllık bir sebze türüdür. Ülkemizde en çok Akdeniz, Ege ve Marmara bölgelerinde salçalık ve sofralık yetiştirilen domates her mevsimde tüketilebilmektedir. Türkiye, 12.615.000 tonun üzerindeki yıllık domates üretimi ile Çin, ABD ve Hindistan la birlikte dünyadaki ilk dört ülkeden birisidir (TUİK, 2015). Kahramanmaraş ilinde ise 2015 tuik verilerine göre salçalık, sofralık ve örtü altı olmak üzere yaklaşık 90 bin ton üretim yapılmaktadır.

Her mevsim tüketilebilen domates ülkemizde, örtü altı ve açık alanda yetiştirilmekte ve üretimini sınırlayan birçok zararlı ve hastalık etmenleri bulunmaktadır. Domates güvesi (Tuta absoluta (Meyrick) (Lepidoptera: Gelechiidae), zararlılar içerisinde domates yetiştiriciliğinde önemli kayıplara neden olan zararlı türlerden birisidir. T. absoluta, Kuzey Amerika kökenli olup, 2006 yllında İspanya'da tespit edildikten sonra hızla diğer Avrupa ülkelerine bulaşmış ve tüm Akdeniz domates alanlarına yayılmıştır (Arno ve ark., 2009; Urbeneja ve ark., 2009).

Türkiye'de ilk kez 2009 yılında İzmir-Urla domates alanlarında tespit edilen zararlı (Kılıç, 2010), 2010 yılının Ocak ayında örtü altı üretiminin yaygın olduğu Antalya'nın Kumluca ilçesinde görülmüştür (Erler ve ark., 2010). Domates güvesinin Türkiye'de varlığının tespitinden hemen sonra Türkiye'nin Akdeniz, Ege, Marmara ve İç Anadolu bölgelerinde zararlının yayılışı, popülasyonu, doğal düşmanları ve mücadelesine yönelik birçok çalışmalar yapılmıştır (Doğanlar ve ark., 2011; Durmuşoğlu ve ark., 2011; Kılıç, 2011; Karabüyük ve ark., 2011a; Karabüyük ve ark, 2011b; Karut ve ark., 2011; Kasap ve ark., 2011; Konca ve ark., 2011; Tatlı ve Göçmen, 2011; Ünlü, 2011; Mamay ve Yanık 2012; Portakaldalı ve ark., 2013; Erdoğan ve ark., 2014 ve Polat ve ark., 2016).

Bulaşık bölgelerde zararlı ile mücadele edilmediği takdirde domateslerde \% 80-100'lere ulaşan ürün kaybına yol açmakta olup tüm örtü altı ve açık-tarla 
domates üretimini tehdit etmektedir (Topuz, 2011). T. absoluta larva döneminde, domatesin kök hariç yaprak, gövde ve meyvesinde aşırı zarar vermektedir. Yaprakta beslenerek düzensiz galeriler açar, bu galeriler nekrotikleşip kahverengiye dönüşerek bitkinin tamamen kurumasina neden olabilmektedir. Meyvede beslenmesi sonucu meydana gelen yaralanmalar patojen enfeksiyonuna neden olmakta ve meyvelerin pazar değerini düşürmektedir. T. absoluta domatesle birlikte patates, patlican, biber ve yabancı otlarla da beslenebilmektedir (EPPO, 2005; Mahmoud ve ark., 2014, Polat ve ark., 2015).

T. absoluta zararı sonucu oluşan kayıpları önlemek için, daha önce Kahramanmaraş ilin de yapılan çalışmaların daha çok tarım teşkilatları tarafından yapılması ve sadece rapor şeklinde kalması nedeni ile bu çalışma ele alınmıştır. Çalışmada, Kahramanmaraş ili Türkoğlu ilçesinin Kadıoğlu köyünde serada domates yetiştiriciliğinde $T$. absoluta'nın ilk ergin uçuş zamanı, popülasyonun en yüksek olduğu dönemler, tahmini döl sayısı ve kelebeklerin seralarda aktif olduğu dönemlerin belirlenmesi amaçlanmıştır.

\section{MATERYAL ve METOD}

Çalışma, Kahramanmaraş iline bağlı Türkoğlu ilçesinin Kadıŏlu köyünde yürütülmüştür (Şekil 1). Çalışmada Domates güvesi T. absoluta ile bulaşık domates serası ve delta tipi tuzaklar materyal olarak kullanılmıştır.

Çalışma, 2011 yılı şubat-temmuz ayları olmak üzere 1 üretim sezonu boyunca 1,5 da büyüklüğünde, plastik örtü materyali ile kaplanmış, domates seralarında gerçekleştirilmiştir. Çalışma boyunca, 2011 yılı baharyaz sezonunda; Kadıoğlu köyünde 8 adet serada ergin çıkış sayısı gözlenmiştir. Bu çalışmada; fideler şubat ve mart aylarında dikilmiştir. Domates bitkisinin fenolojik dönemleri; genç fide, büyüme ve vejetatif gelişme, çiçeklenme ve meyve tutumu, meyve gelişimi, meyve olgunlaşması gibi vejetasyon dönemlerine göre $T$. absoluta'nın mart, nisan, mayıs, haziran ve temmuz ayları içerisinde periyodik olarak tuzaklar haftada bir kontrol edilerek, sayımlar yapılmış ve popülasyon yoğunluğu belirlenmiştir. T. absoluta 'ya karşı nisan ayından itibaren farklı tarihlerde rastgele birçok insektisit uygulaması yapılmıştır.

\section{BULGULAR}

Kahramanmaraş ili Türkoğlu ilçesi Kadığlu köyü seralarında yapılan çalışmalarda elde edilen veriler Şekil $1,2,3,4,5,6,7$ ve 8 'de verilmiştir.

Bir nolu serada T. absoluta erginlerinin 3 tepe noktas1 oluşturduğu görülmüştür (Şekil 1). İlk tepe noktası 31 Mart, ikinci tepe noktası 17 Mayıs ve son tepe noktası ise 8 Haziran tarihinde gerçekleşmiştir. $\mathrm{Bu}$ tepe noktalarında, tuzak başına Kadığlu köyünde 1 nolu serada sırasıyla 205, 325 ve 325 adet ergin yakalanmıştır (Şekil 1). Toplam olarak tuzaklarda yakalanan ergin sayıs1 1834 adet olarak gerçekleşmiştir.

İki nolu domates serasında, T. absoluta erginlerinin 2 tepe noktası olduğu görülmüş, 1 ve 2 . Tepe noktaları sırası ile 6 Mayıs ve 10 Haziran tarihinde gerçekleşmiştir (Şekil 2). Şekil 2'e göre 2. tepe noktasında, tuzak başına Kadığlu köyünde 2. serada 486 ergin yakalanmıştır. 2. tepe noktasından sonra en düşük ergin sayısı 17 Haziranda 105 adet ergin yakalanmıştır. Toplam olarak bu serada tuzaklarda yakalanan ergin sayısı 1602 olmuştur.

3 nolu domates serasinda T. absoluta erginlerinin 2 tepe noktası oluşturduğu gözlenmiştir (Şekil 3). 1. tepe noktası 22 Nisan, ikinci tepe noktas 10 Haziran tarihinde gerçekleşmiştir.

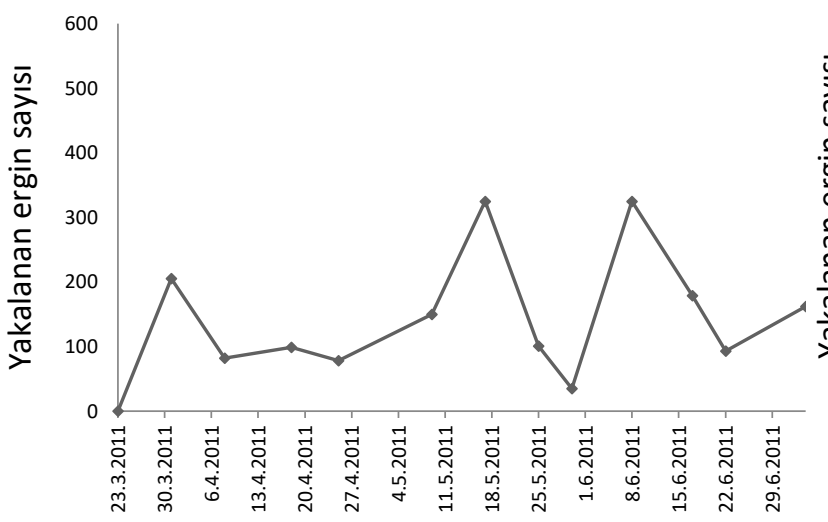

Tarih

Şekil 1. Türkoğlu (Kadığlu köyü) 1 nolu domates serasında Delta tipi tuzaklarda yakalanan T. absoluta ergin sayıları

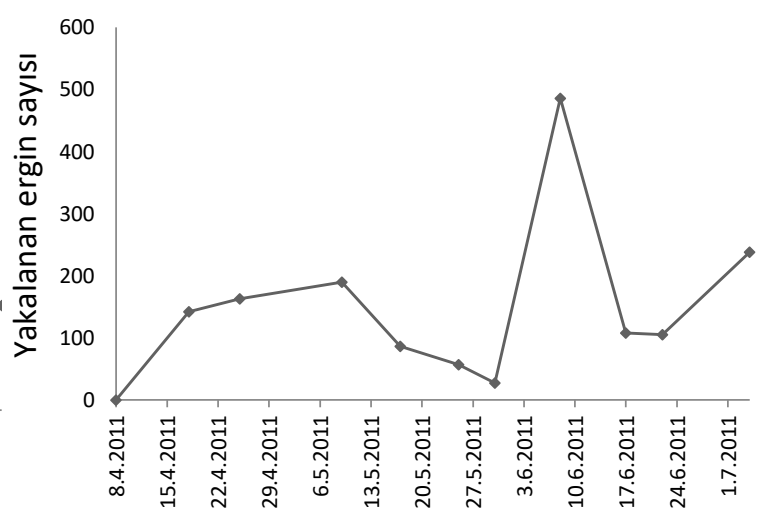

Tarih

Şekil 2. Türkoğlu (Kadığlu köyü) 2 nolu domates serasında Delta tipi tuzaklarda yakalanan T. absoluta ergin sayıları 


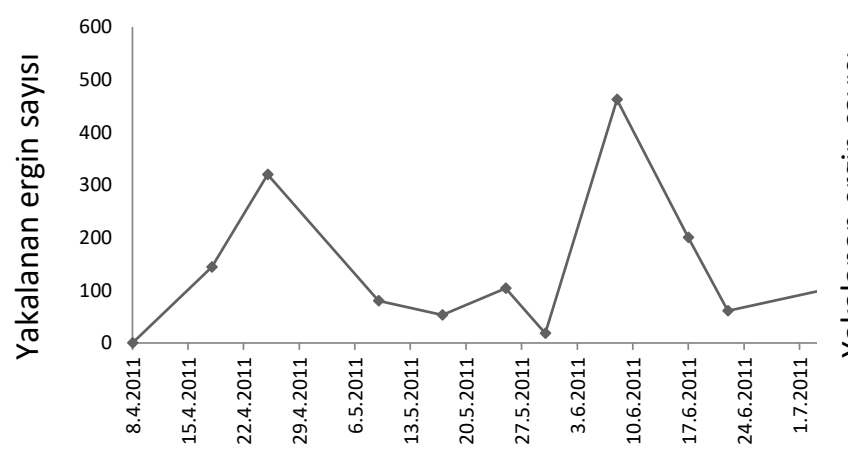

Tarih

Şekil 3. Türkoğlu (Kadıoğlu köyü) 3 nolu domates serasinda Delta tipi tuzaklarda yakalanan T. absoluta ergin sayıları

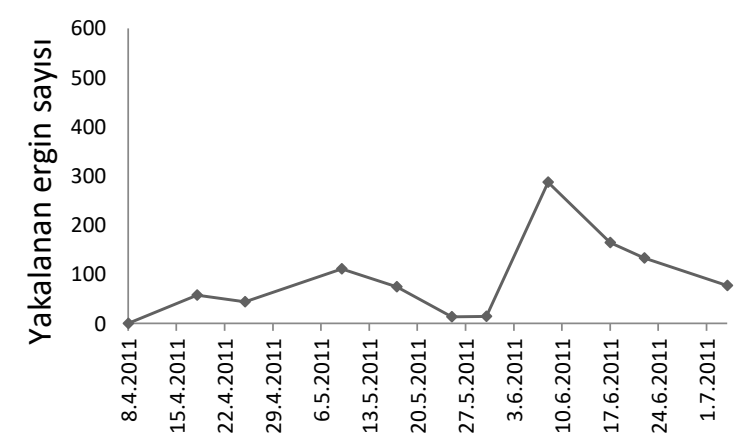

Tarih

Şekil 5. Türkoğlu (Kadığlu köyü) 5 nolu domates serasında Delta tipi tuzaklarda yakalanan T. absoluta ergin sayıları

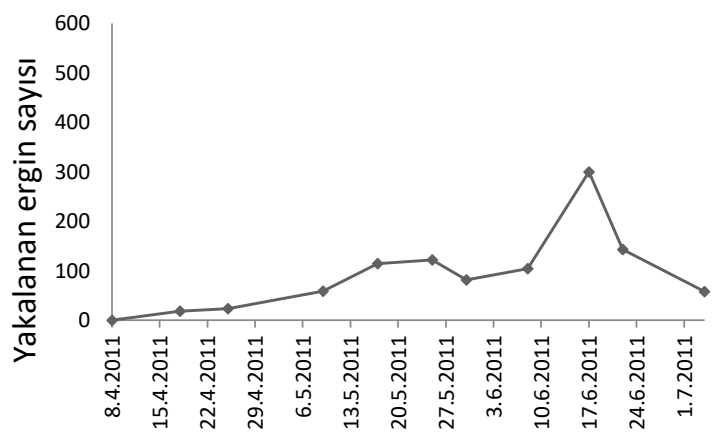

Tarih

Şekil 7. Türkoğlu (Kadığlu köyü) 7 nolu domates serasinda Delta tipi tuzaklarda yakalanan $T$. absoluta ergin sayıları

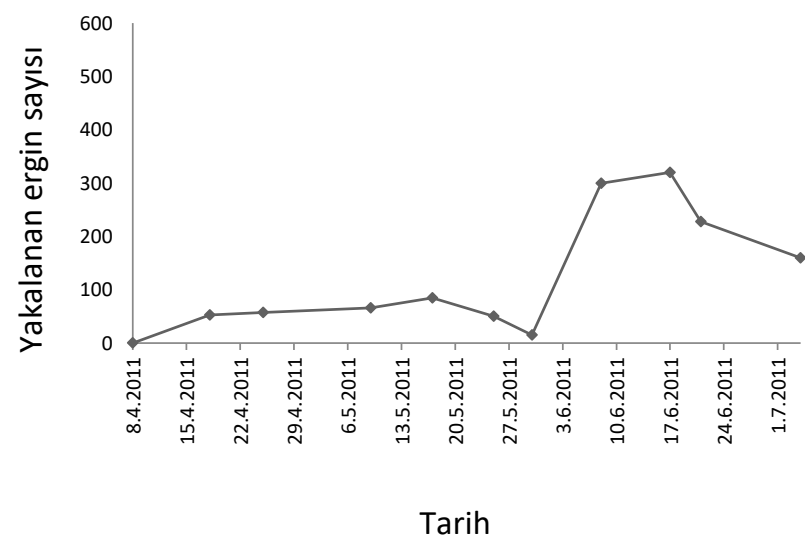

Şekil 4. Türkoğlu (Kadıŏglu köyü) 4 nolu domates serasinda Delta tipi tuzaklarda yakalanan T. absoluta ergin sayıları

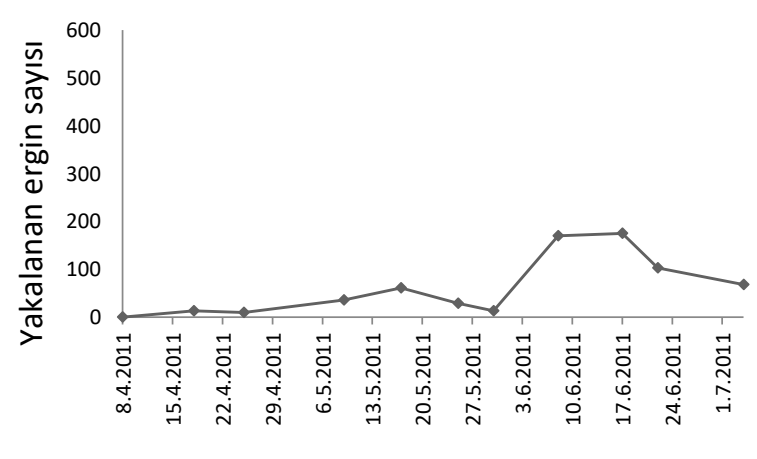

Tarih

Şekil 6. Türkoğlu (Kadığlu köyü) 6 nolu domates serasinda Delta tipi tuzaklarda yakalanan T. absoluta ergin sayıları

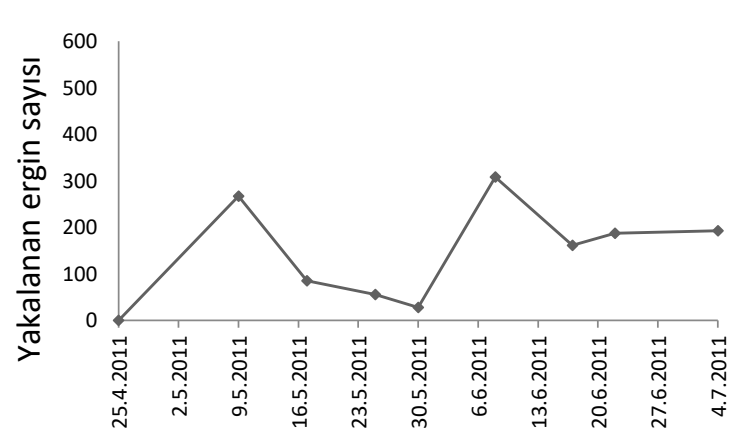

Tarih

Şekil 8. Türkoğlu (Kadığlu köyü) 8 nolu domates serasindaDelta tipi tuzaklarda yakalanan $T$. absoluta ergin sayıları 
Şekil 3'e göre bu tepe noktalarında, tuzak başına Kadıŏlu köyünde 3. serada sirasıyla 320 ve 462 adet ergin yakalanmıştır. Tepe noktalarından sonra en düşük ergin sayıs1 sirasiyla 30 Mayısta 18 adet ve 22 Haziran tarihinde 61 adet ergin yakalanmıştır. Toplamda tuzaklarda 1543 ergin yakalanmıştır.

4 nolu domates serasinda $T$. absoluta erginlerinin 1 tepe noktası olduğu görülmüştür. Tepe noktası 17 Haziran tarihinde gerçekleşmiştir. Şekil 4'e göre bu tepe noktasında, tuzak başına Kadığlu köyünde 4. serada 320 adet ergin yakalanmıştır. Tepe noktasından sonra en düşük ergin sayısı 4 Temmuz tarihinde 160 adet ergin yakalanmıştır. Toplamda tuzaklarda 1334 adet ergin yakalanmıştır.

5 nolu domates serasinda $T$. absoluta erginlerinin 2 tepe noktası olduğu görülmüştür. 1. tepe noktası 9 Mayıs, 2. tepe noktası 8 Haziran tarihinde gerçekleşmiştir. Şekil 5'e göre bu tepe noktalarında, tuzak başına Kadıŏlu köyünde 5. serada sirasiyla 111 ve 287 adet ergin yakalanmıştır. Tepe noktalarından sonra en düşük ergin sayıs1 sirasiyla 25 Mayista 13 adet ve 4 Temmuz tarihinde 77 adet ergin yakalanmıştır. Toplamda tuzaklarda 974 ergin yakalanmıştır.

6 nolu domates serasinda T. absoluta erginlerinin 1 tepe noktası olduğu görülmüştür. Tepe noktası 17 Haziran tarihinde gerçekleşmiştir. Şekil 6'ya göre bu tepe noktasında, tuzak başına Kadığlu köyünde 6. serada 175 adet ergin yakalanmıştır. Tepe noktasından sonra en düşük ergin sayısı 4 Temmuz tarihinde 68 adet ergin yakalanmıştır. Toplamda tuzaklarda 678 adet ergin yakalanmıştır.

7 nolu domates serasinda T. absoluta erginlerinin 2 tepe noktası olduğu görülmüştür. 1. tepe noktası 25 Mayıs, 2. tepe noktası 17 Haziran tarihinde gerçekleşmiştir. Şekil 7'e göre bu tepe noktalarında, tuzak başına Kadığlu köyünde 7. serada sırasıyla 122 ve 300 adet ergin yakalanmıştır. Tepe noktalarından sonra en düşük ergin sayısı sırasıyla 30 Mayıs tarihinde 72 adet ve 4 Temmuz tarihinde 58 adet ergin yakalanmıştır. Toplamda tuzaklarda 1022 adet ergin yakalanmıştır.

8 nolu domates serasinda $T$. absoluta erginlerinin 2 tepe noktası olduğu görülmüştür. İlk tepe noktası 9 Mayıs, 2. tepe noktası 8 Haziran tarihinde gerçekleşmiştir. Şekil 8'e göre bu tepe noktalarında, tuzak başına Kadığlu köyünde 8. serada sırasıyla 267 ve 308 adet ergin yakalanmıştır. Tepe noktalarından sonra en düşük ergin sayısı sırasıyla 30 Mayıs tarihinde 28 adet ve 17 Haziran tarihinde 161 adet ergin yakalanmıştır. Toplamda tuzaklarda 1285 adet ergin yakalanmıştır.

\section{TARTIŞMA ve SONUÇ}

Kahramanmaraş ili Türkoğlu ilçesi Kadıŏlu köyünde 8 farklı serada yürütülen çalışma sonucunda, yapılan kontrollerde $T$. absoluta'nın domates bitkilerinin daha çok yaprak ve meyvelerinde zarar oluşturduğu gözlenmiştir. Tuzakların kurulduğu 8 serada yakalanan ergin sayısı tuzak başına en fazla sırasıyla 325, 486, 462, 320, 287, 175, 300, 308 adet olarak bulunmuştur. $T$. absoluta'nın pupa dönemini yaprak, dal ve meyve üzerinde geçirdiği tespit edilmiştir. Zararlının kış aylarında seralarda zarar yaptığı, konukçu ve iklim istekleri sağlandığında diyapoza girmeden yaşamını sürdürebildiği saptanmıştır. Kahramanmaraş koşullarında T. absoluta'nın en az dört döl verdiği ve bu durumun 8 serada farklı yetiştiricilerin uyguladığ 1 insektisit miktarının T. absoluta 'nın yaptığı tepe sayısına etki ettiği belirlenmiştir. Portakaldalı ve ark. (2013)'nın Doğu Akdeniz ve Güneydoğu Anadolu Bölgeleri'nde yaptıkları çalışmada Kahramanmaraş ilinde T. absoluta ile bulaşıklık \% 30.67 iken, 2012 yılında bu oran düşerek \% 15.94 olarak belirlemişlerdir. Barrientos ve ark. (1998), T. absoluta'nın $21.7^{\circ} \mathrm{C}$ sıcaklıkta bir dölünü 23.8 günde tamamladığını belirtmiştir. Bu çalışmada seradaki ortalama sıcaklık $22{ }^{\circ} \mathrm{C}$ olduğundan zararlının bir dölünüyaklaşık bir ayda tamamladığını belirlenmiştir. Tuzaklardaki kapsüllerin değiştirildiği haftalarda ve eşey feromon tuzaklarında bulunan yapışkan kısmının değiştirildiği tarihlerinde popülasyon artışının olduğu saptanmıştır.

Sonuç olarak, zararlının popülasyonunun çok yoğun olduğu tarihlerde seralardaki tuzak sayılarının artırılması ve kapsüllerin sı aralıklarla değiştirilmesi gerekmektedir. Topuz ve ark., (2016) Batı Karadeniz de yaptıkları çalışmada; açık alanda tuzakların başarılı olabilmesi için iyi tarım uygulaması yapılan kontrollü tarlalarda üretim ve çevrede domatesten farklı ürünlerin çoğunlukla yetiştirildiği dolayısıyla zararlı geçişinin az olduğu yerlerde tuzakların T. absoluta'ya karşı daha başarılı olacağını belirtmişlerdir. Gereken önlemler alınmadığında, ülkemizde ve bölgemizde zararlının domates üretim alanlarında önemli ekonomik kayıplara neden olacağı tespit edilmiştir. Örtü altı yetiştiricilikte domatesin önemli zararlılarından biri olan T. absoluta sorununun çözümü için öncelikle seraların teknik eksikliklerinin giderilmesi, yapılarının optimize edilmesi ve bulaşık bitkilerin uzaklaştırılması, sera giriş çıkışının ve havalandırma işleminin yapıldığı yerlere zararlının giremeyeceği sıklıkta tül ve benzeri yapıların kullanılması gibi kültürel uygulamaların yapılması gerekmektedir.

*Bu makale Uluslararası Katılımlı Türkiye VI. Bitki Koruma Kongresin de poster olarak sunulmuştur.

\section{KAYNAKLAR}

Arno J, Sorribas R, Prat M, Matas M, Pozo C, Rodríguez D, Garreta A, Gomez A, Gabarra R 2009. Tuta absoluta, a new pest in IPM tomatoes in the northeast of Spain. IOBC/WPRS Bulletin, 49: 203-208.

Barrientos ZR, Apablaza HJ, Norero SA, Estay PP 1998. Threshold temperature and thermal constant for development of the South American tomato moth, Tuta absoluta (Lepidoptera, Gelechiidae). Ciencia e Investigacion Agraria, 25, 133-137 (in Spanish).

Doğanlar M, Yildırım AE, Yiğit A 2011. Sera domateslerinde zararlı Tuta absoluta (Meyrick) (Lepidoptera: Gelechidae) mücadelesinde çevre dostu bazı ilaçların etkileri, 54. Türkiye IV. Bitki Koruma Kongresi, 28-30 Haziran 2011, Kahramanmaraş 496 s. 
Durmuşoğlu E, Hatipoğlu A, Balcı H 2011 Bazı bitkisel kökenli insektisitlerin laboratuvar koşullarında Tuta absoluta (Meyrick, 1917) (Lepidoptera: Gelechiidae) larvalarına etkileri araştırılmısı. Turk. Entomol. Derg., 35 (4): 651-663

EPPO 2005. Tuta absoluta. Data sheets on quarantine pests. European and Mediterranean Plant Protection Organization Bulletin 35: 434-435 (Access date: 22.04.2010).

Erdoğan P, Barış A, Alpkent YN 2014. Orta Anadolu bölgesinde Domateslerde zararlı olan Domates güvesi [Tuta absoluta Meyrick (Lepidoptera: Gelechiidae)]'nin sürveyi ile popülasyon takibi. Bitki Koruma Bülteni, 54(3): 255-265.

Erler F, Can M, Erdoğan M, Ates AO, Pradier T 2010. New record of Tuta absoluta (Meyrick) (Lepidoptera: Gelechiidae) on greenhouse-grown tomato in Southwestern Turkey (Antalya). Journal of Entomological Science, 45 (4): 392-393.

Karabüyük F, Portakaldalı M, Ulusoy MR 2011a. Doğu Akdeniz Bölgesi Sebze alanlarında Domates Yaprak Galeri Güvesi [Tuta absoluta (Meyrick)]'nin Yayılışı ve Konukçuları, Türkiye IV. Bitki Koruma Kongresi, 28-30 Haziran 2011, Kahramanmaraş, 496 s.

Karabüyük F, Horuz S, Aysan Y, Ulusoy MR 2011b. Domates yaprak galeri güvesi (Tuta absoluta (Meyrick))'nin biyolojik mücadelesine yönelik ön çalışmalar, Türkiye IV. Bitki Koruma Kongresi, 2830 Haziran 2011, Kahramanmaraş, 496s.

Karut K, Kazak C, Döker İ, Ulusoy MR 2011. Mersin ili domates seralarında Domates yaprak galeri güvesi Tuta absoluta (Meyrick, 1917) (Lepidoptera: Gelechiidae)'nın yaygınlığı ve zarar durumu. Türkiye Entomoloji Dergisi, 35(2): 339-347.

Kasap İ, Gözel U, Özpınar A 2011. A new pest in tomatoes; the tomato borer, Tuta absoluta (Meyrick) (Lepidoptera: Gelechiidae). Proceedings of Çanakkale Agriculture Symposium (Yesterday, Today, Future), Çanakkale Onsekiz Mart University, Agriculture Faculty, Çanakkale, 284-287.

Kilıç, T., 2010. First record of Tuta absoluta in Turkey. Phytoparasitica, 38 (3): 243-244.

Kılıç T 2011. Domates güvesi [Tuta absoluta (Meyrick)] (Lepidoptera: Gelechidae)'nin Türkiye'deki yayılış1 ve mücadelesine yönelik alınan önlemler, 42. Türkiye IV. Bitki Koruma Kongresi, 28-30 Haziran 2011, Kahramanmaraş, $496 \mathrm{~s}$.

Konca E, Pour A.D, Erdoğan T, Güz N, Gürkan MO 2011. Domates Güvesi'nin [Tuta absoluta (Meyrick)] (Lepidoptera: Gelechidae) detoksifikasyon enzimlerinin karakterizasyonu, 18. Türkiye IV. Bitki
Koruma Kongresi, 28-30 Haziran 2011, Kahramanmaraş, $496 \mathrm{~s}$.

Mahmoud YA, Ebadah IMA, Abd-Elrazik AS, AbdElwahab TE, Deif SH 2014. Efficiency of Different Colored Traps Baited with Pheromone in Capturing Tomato Adult Moth, Tuta absoluta (Meyrick)(Lepidoptera: Gelechiidae) during Summer Plantation. World Appl Sci J., 30 (4): 406-412.

Mamay M, Yanık E 2012. Şanlıurfa'da domates alanlarında Domates güvesi [Tuta absoluta (Meyrick) (Lepidoptera: Gelechiidae)]'nin ergin popülasyon gelişimi Determination of adult population development of Tomato leafminer [Tuta absoluta (Meyrick) (Lepidoptera: Gelechiidae)] in tomato growing areas in Şanlıurfa. Türk. Entomol. Bülteni, 2 (3): 189-198.

Polat B, Özpınar A., Şahin AK 2016. Studies of selected biological parameters of tomato leafminer Tuta absoluta (Meyrick), (Lepidoptera: Gelechiidae) under natural conditions. Phytoparasitica, 44: 195202.

Portakaldalı M, Öztemiz S, Kütük H, Büyüköztürk HD, Ateş AÇ 2013. Doğu Akdeniz ve Güneydoğu Anadolu Bölgeleri'nde Tuta absoluta (Meyrick) (Lepidoptera: Gelechiidae)'nın yayılış durumu. Türk Entomol. Bülteni, 3 (3): 133-139.

Tatlı E, Göçmen H 2011. Domates Güvesi [Tuta absoluta (Meyrick)] (Lepidoptera: Gelechidae)'nin Bat1 Akdeniz Bölgesi domates üretim alanlarında yayılışının ve popülasyon değişiminin izlenmesi, 271. Türkiye IV. Bitki Koruma Kongresi, 28-30 Haziran 2011, Kahramanmaraş, 496 s.

TUIK, 2015. https://biruni.tuik.gov.tr/bitkiselapp/ bitkisel.zul.

Topuz, E., 2011. Domates güvesi Tuta absoluta. (Web sayfasi: http://www.sarivelilertarim.gov.tr/upload/ dosyalar/) (Erişim tarihi: Ağustos 2012).

Topuz, E., Tekşam, İ., Karataş, A., 2016. Batı Akdeniz Bölgesi'nde Tuta absoluta (Meyrick) (Lepidoptera:Gelechiidae)'nın biyoteknik mücadele olanaklarının araştırılması. Bitki Koruma Bülteni, 56(3): 239-258.

Urbaneja A, Monto H, Molla O 2009. Suitability of the tomato borer Tuta absoluta as prey for Macrolophus pygmaeus and Nesidiocoris tenuis. Journal of Applied Entomology, 133 (4): 292-296.

Ünlü L 2011. Domates Güvesi, Tuta absoluta (Meyrick)'nın Konya ilinde örtüaltında yetiştirilen domateslerdeki varlığı ve popülasyon değişimi. Selçuk Üniversitesi Selçuk Tarım ve Gıda Bilimleri Dergisi, 25 (4): 27-29. 